\title{
Мотивация участников краудфандинговых проектов в сфере науки и просвещения
}

М.Н. ГОРДЕЕВ, Национальный исследовательский университет «Высшая школа экономики», Москва. E-mail: mngordeev@gmail.com

Ограниченные возможности государственного бюджета по финансированию российской науки делают актуальным вопрос привлечения дополнительных финансовых ресурсов, в частности, через механизм краудфандинга. В работе на основе социологического опроса участников отечественных и зарубежных научных краудфандинговых проектов проведен анализ их мотивации и составлен усредненный портрет спонсора таких проектов. Также определены сферы, в которых краудфандинг может быть применен с наибольшей эффективностью, чтобы дополнить сложившуюся в России систему финансирования науки и просвещения.

Ключевые слова: научный краудфандинг, финансирование ученых, мотивация участников, Experiment, Planeta

Проблемы финансирования науки как в России, так и за рубежом во многом схожи. Главные из них - высокая конкуренция за получение средств и несовершенство механизмов их распределения. В частности, последних отличает консерватизм экспертов, рецензирующих заявки, отвлечение ученых для прохождения большого объема бюрократических процедур, а также сложности в получении грантов для молодых ученых [Миндели, 2009].

В сфере распределения государственных средств на фундаментальную науку наметилось явное смещение приоритетов в сторону крупных грантов, при одновременном сокращении финансирования небольших инициативных проектов. В 2016 г. Российский фонд фундаментальных исследований (РФФИ), который поддерживает небольшие проекты по широкому кругу научных областей, был объединен с Российским гуманитарным научным фондом, однако бюджет укрупненного РФФИ остался прежним. Тогда как увеличение расходов на фундаментальные исследования происходит через Российский научный фонд, который ориентирован на крупные гранты: в 2018 г. взнос в этот фонд 
из федерального бюджета составит 7665 млн руб., а в 2019 г. и 2020 г. - по 13525 млн руб. ${ }^{1}$

В бюджетном финансировании прикладных исследований приоритет отдается НИОКР в области национальной обороны, по остальным направлениям уровень поддержки сокращается. Так, в 2017 г. расходы на прикладные научные исследования в области национальной обороны и безопасности почти вдвое превышали расходы на исследования в области национальной экономики, а к 2019 г. объем финансирования последних сократится на 23,8\% относительно уровня 2017 г. [Дежина, 2017. C. 465]. Также замораживается финансирование фонда содействия развитию малых форм предприятий в научно-технической сфере (фонда содействия инновациям): в 2018 г. объем финансирования составит 3925 млн руб., в 2019 г. - 4004 млн руб., в 2020 г. -4009 млн руб. ${ }^{2}$

Ввиду ограниченности ресурсов у государства нет возможности для удовлетворения всех общественных запросов. В связи с этим все более актуальным становится поиск альтернативных источников и способов финансирования научных исследований. Определенную нишу здесь может заполнить так называемое «народное финансирование» - краудфандинг. В рамках этого механизма инициатор проекта (исследователь) размещает на специальной интернет-площадке информацию о проекте и объеме средств, необходимых для его реализации. Посетители сайта, заинтересовавшиеся проектом (спонсоры), перечисляют свои средства на счет крауд-площадки. Если за заранее оговоренный срок удастся набрать нужную сумму, она передается исследователю, в противном случае средства возвращаются спонсорам.

Краудфандинг не может разрешить всех проблем сложившейся системы финансирования науки, однако он обладает рядом преимуществ и может служить ее дополнением. Так, публичное представление проекта и конкурентная основа сбора средств способствуют повышению качества проработки заявки и личной ответственности исследователя за результаты; нетрадиционное распределение средств обеспечивает разнообразие

\footnotetext{
${ }^{1}$ Федеральный закон от 05.12.2017 №362-Ф3 (ред. от 03.07.2018)

«О федеральном бюджете на 2018 год и на плановый период 2019 и 2020 годов»

${ }^{2}$ Федеральный закон от 05.12.2017 №362-Ф3 (ред. от 03.07.2018)

«О федеральном бюджете на 2018 год и на плановый период 2019 и 2020 годов»
} 
подходов к решению научных проблем; этот механизм позволяет привлекать средства сравнительно быстро и при минимальном уровне бюрократических процедур. Как отмечается в зарубежных работах, краудфандинг может быть полезен для финансирования областей, на которые выделяется недостаточно средств из традиционных источников (например, исследования редких болезней) [Lorenzo, 2017], для поддержки молодых ученых [Siva, 2014], a также инноваций [Ozdemir at el., 2015] (поскольку спонсоры в краудфандинге в большей степени склонны поддерживать рискованные поисковые проекты).

Из недостатков данного механизма в первую очередь называются отсутствие формальных процедур проверки качества выполнения научной работы, а также контроля за расходованием средств. Однако системные исследования научного краудфандинга [Siva, 2014] показывают, что по мере развития механизма связанные с этими недостатками риски сокращаются. Так, в подавляющем большинстве случаев проекты выполняют профессиональные ученые, а некоторые крауд-площадки вообще не допускают к участию исследователей, не аффилированных с научными организациями или лабораториями. Результаты исследований чаще всего публикуются в научных журналах, со всеми сопутствующими процедурами проверки и верификации. Дополнительную оценку качества результатов исследования обеспечивают сами спонсоры через механизм коллегиальной проверки (peer-review mechanism). Отличительной его особенностью является то, что спонсоры могут принять участие в проекте не только тогда, когда он уже завершен, а еще на этапе его разработки и выполнения, а коллективное обсуждение позволяет на ранних этапах выявить слабые стороны проекта и выработать способы их устранения. В работе [Mollick, Robb, 2016] показано, что случаи мошенничества для краудфандинга вообще (не только научного) крайне редки, потому что сообщество спонсоров способно качественно оценить перспективы проекта и благонадежность его автора.

Кроме того, на крауд-площадках, как правило, применяется ряд формальных процедур, как то: идентификация личности автора, проверка заявок на предмет достоверности данных, а также реалистичности достижения поставленной исследовательской цели [Weigmann, 2013]. Отметим также, что автор проекта при- 
влекает средства под собственную репутацию, что становится дополнительной гарантией добросовестного выполнения проекта. Практика показывает, что отмеченные недостатки не являются серьезным препятствием к использованию этого механизма.

C точки зрения социальной значимости краудфандинга, во-первых, распространение этого механизма способствует развитию в обществе культуры самоорганизации и социальной ответственности, что в будущем может дать дополнительный толчок к развитию меценатства и эндаумента в России. Во-вторых, он предполагает выстраивание диалога между учеными и обществом, что, с одной стороны, служит популяризации науки, с другой - способствует выработке у исследователей навыков коммуникации и преодоления их замкнутости внутри довольно узкого научного сообщества.

\section{Данные и метод}

Для анализа мотивации участников краудфандиговых проектов изучались проекты, представленные на двух площадках - международной Experiment.com, которая специализируется на научных исследованиях, и российской Planeta.ru (проекты, проведенные в разделе «Наука»).

На конец 2017 г. на площадке Experiment.com было проведено 750 успешных научных краудфадинговых кампаний, которые совокупно привлекли более 6,1 млн долл. США от 41 тыс. спонсоров. В социологическом опросе на этой площадке приняли участие 129 авторов (доверительный интервал - 8\%, доверительная вероятность - 95\%), из которых 54 человека имели ученую степень, а также 278 спонсоров (доверительный интервал - 6\%, доверительная вероятность - 95\%). Все участники проектов имели одинаковую возможность принять участие в опросе.

На площадке Planeta.ru анализировались 64 проекта, размещенные в разделе «Наука», которые совокупно привлекли 22,5 млн руб. от 10,4 тыс. спонсоров. Поскольку практически все они относились скорее к сфере просвещения (а не проведения научных исследований), опрос среди авторов не проводился. Но спонсоров проектов мы все же попросили ответить на вопросы анкеты. В результате откликнулся 91 человек (доверительный интервал - 10\%, доверительная вероятность - 95\%). При этом отметим, что приглашение к участию в опросе имели 
возможность получить только те спонсоры, которые посещали сайт Planeta.ru в период с августа по декабрь 2017 г., так что полученные данные характеризуют не всю генеральную совокупность участников, а лишь тех, кто периодически заглядывает на сайт крауд-площадки.

\section{Общие характеристики изучаемых площадок}

Площадка Experiment была учреждена в 2013 г. и на конец 2017 г. на ней было проведено 750 успешных краудфандинговых кампаний. Из общего количества проектов 84\% были аффилированы с крупными университетами, лабораториями и исследовательскими центрами, $6 \%$ - с неправительственными организациями и фондами (в основном это проекты в сфере экологии и защиты окружающей среды), и только 10\% проектов были проведены независимыми исследователями и частными организациями.

Наибольшую долю средств (88\%) смогли собрать проекты, относящиеся к сфере наук о жизни (в первую очередь - биологии, экологии и медицины), около $8 \%$ привлечено на точные науки, оставшиеся - на социальные науки. Судя по данным о географической принадлежности, указанной авторами ${ }^{3}$, были успешно профинансированы проекты из 33 стран, в том числе - США (80\%), Австралии, Англии и Канады (в общей сложности $-10 \%)$, и других. На один проект в среднем было привлечено около 4,7 тыс. долл. США (медиана - 3,5 тыс. долл. США) от 50 спонсоров, так что вклад каждого из них составляет около 95 долл.

В России отсутствуют специализированные площадки для научного краудфандинга, но на площадке Planeta.ru в разделе «Наука» было проведено 64 успешных кампании, собравшие 22,5 млн руб. В основном это проекты в сфере просвещения и популяризации науки (21,7 млн руб.), непосредственно на научные исследования и поддержку ученых было собрано около 0,8 млн руб. Проекты сильно различаются по размеру аккумулируемых сумм. Шесть самых крупных из них собрали в общей сложности 12,9 млн руб., в том числе два раунда финансирования фонда «Эволюция» (3,9 млн руб.) и выпуск

${ }^{3}$ Географическая принадлежность указана в 75\% от общего числа успешных проектов 
учебника истории под авторством Е. Ю. Спицына (4 млн руб.). Средние проекты привлекли в целом 8,5 млн руб. на 30 проектов (около 300 тыс. руб. на отдельный проект), а 28 малых проектов собрали в общей сложности 1,3 млн руб. (около 50 тыс. руб. каждый). В поддержке этих инициатив приняли участие более 10,4 тыс. спонсоров, средний вклад каждого из них составил около 1,9 тыс. руб.

\section{Результаты исследования}

\section{Основная мотивачия для авторов проектов}

В ходе опроса мы просили авторов проектов с платформы Experiment оценить достаточность собранных средств. Согласно полученным данным, в $84 \%$ случаев собранная сумма покрывает только часть расходов на запланированное исследование. Это связано с тем, что авторы чаще всего прибегают к механизму краудфандинга в поисках недостающего финансирования, которое они не могут покрыть за счет традиционных источников или собственных средств.

Среди основных причин обращения к крауд-сообществу респонденты из числа авторов назвали следующие:

- традиционные источники покрывают только часть расходов на данное исследование (26\% ответивших);

- высокая конкуренция за гранты (21\%);

- традиционные источники не покрывают расходы на данное исследование (18\%);

- традиционные источники становятся доступны только после завершения предварительных работ, которые были профинансированы через краудфандинг (12\%).

Интересные особенности обнаруживаются при сравнении ответов респондентов, имеющих научную степень и без нее. Так, исследователи уровня $\mathrm{Ph} . \mathrm{D}$. наиболее распространенной причиной использования краудфандинга (29\%) назвали тот факт, что традиционные источники вообще не покрывают расходы на запланированное ими исследование. Это косвенно свидетельствует о том, что краудфандинг позволяет финансировать более широкий спектр научных инициатив и в некоторой степени компенсировать несовершенство существующей системы распределения финансирования в науке. 
Для исследователей без ученой степени более важной причиной является то, что полученный грант не покрывает все расходы на исследование (31\%). На наш взгляд, само наличие гранта говорит о том, что то или иное исследование находится в русле «научного мейнстрима», поддерживаемого традиционной системой финансирования. Кроме того, исследователи без ученой степени заметно чаще своих более опытных коллег сталкиваются с большим количеством бюрократических процедур для получения бюджетного финансирования, а $7 \%$ из них отмечают, что такое финансирование недоступно на их нынешней формальной позиции в научном учреждении. Эти данные косвенно подтверждают эффективность краудфандинга для поддержки молодых ученых и финансирования их инициатив.

Мы просили авторов оценить также удовлетворенность от проведенной краудфандинговой кампании, и количество положительных ответов достигло 92\%. При этом $70 \%$ от общего числа респондентов заявили, что намерены использовать данный механизм и в будущем.

\section{Портрет спонсора научного краудфандинга}

Заметные различия в поведении представителей разных возрастных групп, изучаемые теорией поколений [Howe, Strauss, 1992], верны и в отношении механизма краудфандинга. Так, в исследовании Терри [Terry, 2015] показано, что представители миллениалов (к ним относят людей, рожденных между 1980-2000 гг.) более других склонны участвовать в «народном финансировании». И результаты наших опросов показывают, что в случае научного краудфандинга доля представителей поколения миллениалов действительно существенно выше возрастного распределения экономически активного населения на обеих исследованных площадках (табл. 1).

Анализ профессиональной принадлежности спонсоров научного краудфандинга обнаруживает высокую долю представителей научной и околонаучной сферы: для площадки Experiment она составляет 55\% респондентов (из них 11\%-студенты и аспиранты), а на платформе Planeta-39\% (в том числе $15 \%$ студентов и аспирантов). Это подтверждает высказанное предположение о том, что сообщество спонсоров может провести качественную оценку предложенной исследовательской инициативы. 
Таблица 1. Возрастное распределение спонсоров проектов по научному краудфандингу и экономически активного населения в России и США, \%

\begin{tabular}{|l|c|c|c|c|}
\hline \multirow{2}{*}{ Поколение } & \multicolumn{2}{|c|}{ Experiment.com } & \multicolumn{2}{c|}{ Planeta.ru } \\
\cline { 2 - 5 } & $\begin{array}{c}\text { Доля } \\
\text { респон- } \\
\text { дентов }\end{array}$ & $\begin{array}{c}\text { Распределение эко- } \\
\text { номически активного } \\
\text { населения в США* }\end{array}$ & $\begin{array}{c}\text { Доля } \\
\text { респон- } \\
\text { дентов }\end{array}$ & $\begin{array}{c}\text { Распределение эко- } \\
\text { номически активного } \\
\text { населения в России* }\end{array}$ \\
\hline $\begin{array}{l}\text { Z (рожденные после } \\
2000 \text { г.) }\end{array}$ & 0 & 6 & 0 & 4 \\
\hline $\begin{array}{l}\text { Y- миллениалы } \\
\text { (1981-2000 гг.) }\end{array}$ & 48 & 35 & 75 & 36 \\
\hline Х (1966-1980 гг.) & 30 & 27 & 18 & 27 \\
\hline $\begin{array}{l}\text { Бэби-бумеры } \\
\text { (1946-1965 гг.) }\end{array}$ & 20 & 32 & 7 & 33 \\
\hline $\begin{array}{l}\text { Зрелое поколение } \\
\text { (до 1945 г.) }\end{array}$ & 2 & 0 & 0 & 0 \\
\hline
\end{tabular}

Примечание. * По данным национальных служб статистики, на 1 января 2017 г. (по методологии Международной организации труда к экономически активному населению относят граждан в возрасте от 15 до 72 лет).

Высокая доля респондентов из научной и околонаучной сферы отчасти обусловлена тем, что представителям этой профессии легче вникнуть в нюансы финансируемого исследования, а отчасти - социальными контактами автора. По данным И. Борст [Borst, 2017], инициаторы краудфандинговых проектов довольно часто опираются на поддержку своих родных, знакомых и коллег. И наш опрос спонсоров Experiment показал, что действительно $60 \%$ спонсоров были знакомы с автором хотя бы одного проекта, который они поддерживали. В то же время в общем количестве представителей научной и околонаучной сферы доля тех, кто был знаком с автором до начала кампании, составляет 61\%, а тех, кто не был с ним знаком, $-45 \%$.

На отечественной площадке Planeta.ru доля спонсоров из coциальной сети автора составляет лишь 25\%, но и это достаточно значимая величина.

Мы проанализировали аудиторию крауд-площадки по числу поддержанных проектов. Многие из тех, кто спонсировал всего один проект, больше не возвращаются на площадку, и их можно условно отнести к переменной части аудитории. Если же спонсор принял участие в финансировании более одного проекта, значит, он время от времени возвращается на платформу и самостоятельно отслеживает появление новых инициатив, и таких, как он (примерно 44\% респондентов с площадки Experiment и 66\% 
с площадки Planeta ${ }^{4}$, можно считать условно постоянной аудитории. Примечательно, что в среднем на одного «постоянного» спонсора приходится четыре поддержанных проекта на обеих площадках. Очевидно, это проекты разных исследователей, потому что среди наших респондентов-авторов практически нет людей, которые бы инициировали больше одного проекта.

При этом среди спонсоров, знакомых с автором, значительная часть (37\% для Experiment и 65\% - для Planeta) инвестирует и в другие проекты на площадке. Таким образом, привлечение спонсоров из социальной сети авторов способствует формированию постоянной аудитории крауд-площадки и в конечном счете служит развитию механизма общественной поддержки научных исследований.

\section{Мотивачия спонсоров научного краудфандинга}

В качестве основной причины поддержки научного проекта $38 \%$ респондентов с площадки Experiment назвали личное знакомство с его автором. Почти также распространена поддержка проектов из-за их научной ценности $(30 \%)$ и несколько менее - их социальной значимости (16\%). Но несмотря на то, что личные связи на данном этапе преобладают в ряду причин поддержки научного краудфандинга, спонсоры большое внимание обращают на реальную ценность проекта. Даже среди знакомых автора велика доля тех, кто поддерживает проект из-за его научной $(20 \%)$ и социальной $(10 \%)$ значимости, а не просто из-за факта знакомства. А среди тех, кто не знаком с автором, эти причины совокупно достигают 70\%, среди тех, кто поддержал более одного проекта, $-67 \%$. Это позволяет утверждать, что механизм распределения средств через краудфандинг является справедливым и непредвзятым, по крайней мере, в отношении постоянной части аудитории площадки, и по мере ее роста значимость личных контактов автора будет снижаться.

В то же время на платформе Planeta.ru только 19\% респондентов отметили научную ценность поддержанного ими проекта, еще $3 \%$ заявили, что заинтересованы в его результатах. Все прочие

\footnotetext{
${ }^{4}$ Следует принять во внимание, что ввиду способа рассылки приглашений на платформе Planeta, описанного в методологии исследования, существует смещение выборки в сторону постоянной части аудитории этой крауд-площадки, из-за чего результаты о доле респондентов, поддерживающих более одного проекта, могут быть завышены.
} 
причины можно отнести к разряду «меценатских». При этом ни один из участников не указал в качестве основной причины поддержки проекта личное знакомство с автором (табл. 2).

\section{Таблица 2. Опрос спонсоров краудфандинговых проектов}

\begin{tabular}{|c|c|c|c|c|}
\hline \multirow{2}{*}{ Вариант ответа } & \multicolumn{2}{|c|}{ Experiment.com } & \multicolumn{2}{|c|}{ Planeta.ru } \\
\hline & Кол-во & Доля,\% & Кол-во & Доля,\% \\
\hline \multicolumn{5}{|c|}{$\begin{array}{c}\text { Какова была главная причина, по которой Вы поддержали научный краудфандинговый } \\
\text { проект? }\end{array}$} \\
\hline $\begin{array}{l}\text { Поддержка качественной исследовательской инициативы - } \\
\text { научная ценность }\end{array}$ & 84 & 30,2 & 17 & 18,7 \\
\hline $\begin{array}{l}\text { Поддержка важной социальной инициативы- общественная } \\
\text { ценность }\end{array}$ & 44 & 15,8 & 31 & 34,0 \\
\hline $\begin{array}{l}\text { Результаты исследования/предложенное вознаграждение } \\
\text { полезны лично для меня или моих близких }\end{array}$ & 7 & 2,5 & 3 & 3,3 \\
\hline Личное знакомство с автором проекта & 106 & 38,1 & 0 & 0 \\
\hline $\begin{array}{l}\text { Поддержка исследователей, которые недостаточно финан- } \\
\text { сируются из традиционных источников (молодые ученые, } \\
\text { девушки-ученые и проч.) }\end{array}$ & 5 & 1,8 & 6 & 6,6 \\
\hline $\begin{array}{l}\text { Поддержка научной сферы, которая недофинансирована } \\
\text { через традиционные источники }\end{array}$ & 4 & 1,5 & 11 & 12,1 \\
\hline $\begin{array}{l}\text { Личность авторапроекта, егоприверженность деятельности, } \\
\text { которую вы разделяете }\end{array}$ & 15 & 5,4 & 12 & 13,2 \\
\hline $\begin{array}{l}\text { Аффилированность автора проекта с определенной ор- } \\
\text { ганизацией }\end{array}$ & 3 & 1,1 & 0 & 0 \\
\hline Благотворительность & 3 & 1,1 & 9 & 9,9 \\
\hline $\begin{array}{l}\text { Налоговые / финансовые преимущества от спонсорской } \\
\text { деятельности }\end{array}$ & 0 & 0 & 0 & 0 \\
\hline $\begin{array}{l}\text { Следование моде, примеру других людей или простое } \\
\text { любопытство }\end{array}$ & 2 & 0,7 & 0 & 0 \\
\hline Это был мой собственный проект & 4 & 1,5 & 0 & 0 \\
\hline Другое & 1 & 0,3 & 2 & 2,2 \\
\hline Итого & 278 & 100 & 91 & 100 \\
\hline \multicolumn{5}{|c|}{ Какие эмоции у Вас вызывает участие в научном краудфандинге? } \\
\hline Удовлетворение от поддержки общественного блага & 214 & 77,0 & 65 & 73,0 \\
\hline Удовлетворение по другим причинам & 24 & 8,6 & 16 & 18,0 \\
\hline Выполнение долга перед коллегами, близкими и проч. & 24 & 8,6 & 0 & 0,0 \\
\hline Раздражение от того, что к Вам обращаются за деньгами & 3 & 1,0 & 0 & 0,0 \\
\hline Раздражение по другим причинам & 0 & 0 & 1 & 1,1 \\
\hline $\begin{array}{l}\text { Я не испытал никаких эмоций, связанных с краудфандин- } \\
\text { говым проектом }\end{array}$ & 12 & 4,3 & 6 & 6,8 \\
\hline Другое & 1 & 0,5 & 1 & 1,1 \\
\hline Итого & 278 & 100 & 89 & 100 \\
\hline
\end{tabular}


Следует отметить, что в США сумма, направленная на поддержку научных исследований через краудфандинг, не облагается подоходным налогом [Giles, 2012]. Это не является основной мотивацией для поддержки подобных проектов, но служит стимулом для развития научного краудфандинга, который можно было бы взять на вооружение в России.

В ходе опроса мы поинтересовались у спонсоров, насколько удовлетворены они результатами исследования. Часть из них (15\% опрошенных на площадке Planeta и $10 \%$ на Experiment) отметили, что у них не было никаких ожиданий от проекта. Часть (11\% и 15\% для Planeta и Experiment соответственно) на момент проведения опроса еще не получила результаты исследования. Однако на обеих площадках среди тех, кто получил результаты и был в них заинтересован, практически все остались удовлетворены полученными результатами. Учитывая, что среди спонсоров высока доля представителей научной сферы, хорошо знакомых с критериями оценки исследовательской работы, это может служить косвенным свидетельством высокого уровня выполненных работ. Другим таким же свидетельством является высокая готовность респондентов (98-100\%) участвовать в поддержке краудфандиговых проектов в будущем.

\section{Заключение}

Проведённый анализ показывает, что научный краудфандинг может рассматриваться как дополнение к существующей системе финансирования науки. Его положительное воздействие выражается в двух аспектах: в прямом вливании дополнительных средств и некотором компенсировании недостатков существующей системы распределения финансирования. В частности, путем направления доли средств в сферы, выпадающие из спектра научных областей, покрываемых традиционными источниками финансирования науки, а также - на поддержку молодых ученых. Кроме того, краудфандинг зарекомендовал себя как эффективный инструмент для финансирования предварительных работ, необходимых для обоснования заявки на грант.

Несмотря на то, что в России научный краудфандинг охватывает преимущественно просветительские проекты, у него много общих черт с зарубежной практикой, направленной в первую очередь на научные исследования. В частности, и у нас, 
и за рубежом отмечено формирование устойчивых сообществ спонсоров, которые регулярно поддерживают такого рода инициативы, осознают важность научных исследований и выражают готовность участвовать в подобных проектах в будущем. Это позволяет надеяться на перспективы более широкого распространения краудфандинга в России на сферу науки и, в первую очередь, наук о жизни, которым подчас уделяется недостаточно внимания.

Краудфандинг также играет важную социальную роль, потому как способствует формированию в обществе коллаборативной модели поведения, в которой решение общественно значимых вопросов не является прерогативой государственных или частных институтов, а может быть инициировано «снизу».

\section{Литература}

Миндели Л., Черных С. Проблемы финансирования российской науки // Общество и экономика. 2009. № 1.

Дежина И. Раздел 6.5 Состояние науки и инноваций // Российская экономика в 2016 году. Тенденции и перспективы. (Вып.38) В. Мау и др. / Под ред. С.Г. Синельникова-Мурылева, Радыгина А. Д. Ин-т экон. политики им. Е. Т. Гайдара. М.: Изд-во Ин-та Гайдара, 2017. 520 с.

Siva N. Crowdfunding for medical research picks up pace // The Lancet. 2014. Vol. 384, Pp. 1085-1086.

Lorenzo D.S. The place of crowdfunding in the discovery of scientific and social value of medical research // Bioethics. 2017.

Ozdemir V., Faris J. and Srivastava S. Crowdfunding 2.0: the next-generation philanthropy// EMBO report. 2015. Vol. 16. No.3. Pp. 267-271.

Mollick E., Robb A. Democratizing Innovation and Capital Access: The Role of Crowdfunding // California Management Review. 2016. Vol. 58 (2). Pp. 72-87.

Weigmann K. Tapping the crowds for research funding // EMBO report. 2013. Vol. 14. No.12. Pp. 1043-1046.

Howe N., Strauss W. Generations: The History of America's Future. 1584 to 2069. Harper perennial.1992. Pp. 1584-2069.

Terry H.P., Schwartz D., Sun T. The future of finance. Part 3. The Socialization of Finance// Аналитический отчет. Goldman Sachs. 2015. 62 p.

Borst I., Moser C. and Ferguson J. From friendfunding to crowdfunding: Relevance of relationships, social media, and platform activities to crowdfunding performance. New media \& society. 2017. Pp. 19.

Giles J. Finding philanthropy: Like it? Pay for it. Nature. 2012. No. 481. Pp. 252-253. 


\section{Summary}

Gordeev M.N. National Research University Higher School of Economics, Moscow

Science Crowdfunding: Key Motives That Influence Project Participants

Due to limited state resources, allocated for scientific projects in Russia, it is reasonable to consider the attraction of additional financial sources, in particular, via crowdfunding mechanism. The research features specifics of the crowdfunding community: a portrait of an average backer and key motivational factors of the crowdfunding participants. The paper also reveals spheres in which crowdfunding can be applied with the most of efficiency, so that to supplement the existing system of financing science and education in Russia.

Science crowdfunding; financing of scientist; motivation of participants; Experiment; Planeta

\section{References}

Mindeli L., Chernyh S. (2009) Problemy finansirovaniya rossijskoj nauki. Obshchestvo i ehkonomika. Vol. 1. (In Russ.)

Dezhina I. (2017) Razdel Sostoyanie nauki i innovacij. Rossijskaya ehkonomika $v 2016$ godu. Tendencii i perspektivy. Vol. 38. 520 p. (In Russ.)

Siva N. (2014) Crowdfunding for medical research picks up pace. The Lancet, Vol. 384. Pp.1085-1086.

Lorenzo D.S. (2017) The place of crowdfunding in the discovery of scientific and social value of medical research. Bioethics.

Ozdemir V., Faris J. and Srivastava S. (2015) Crowdfunding 2.0: the nextgeneration philanthropy. EMBO report. Vol. 16 (3). Pp. 267-271.

Mollick E., Robb A. (2016) Democratizing Innovation and Capital Access: The Role of Crowdfunding. California Management Review. Vol. 58 (2). Pp. 72-87.

Weigmann K. (2013) Tapping the crowds for research funding. EMBO report. Vol. 14. No.12. Pp. 1043-1046.

Howe N., Strauss W. (1992) Generations: The History of America's Future. Pp. 1584-2069.

Terry H.P., Schwartz D., Sun T. (2015) The future of finance. Part 3. The Socialization of Finance / Equity report. Goldman Sachs. 62 p.

Borst I., Moser C. and Ferguson J. (2017) From friendfunding to crowdfunding: Relevance of relationships, social media, and platform activities to crowdfunding performance. New media \& society. P. 19.

Giles J. (2012) Finding philanthropy: Like it? Pay for it. Nature. Vol 481. Pp. 252-253. 